\title{
CRITÉRIOS PARA AVALIAÇÃO DE GENEROS ORAIS: PERSPECTIVA ENUNCIATIVA DE LINGUAGEM
}

\section{Celia Helena Pelegrini Della Méa* Silvana Silva**}

Resumo: Considerando a Linguística da Enunciação proposta por Flores e Teixeira (2005) e Flores (2013), buscamos promover critérios para avaliação de gêneros orais produzidos em ambientes de ensino e aprendizagem. Tendo por base os gêneros orais: 1 . seminário com arguição; 2. entrevista; e 3. debate regrado, 22 docentes responderam a um formulário on-line sobre a avaliação desses gêneros orais. Foram observadas divergências na avaliação, fato que tornou necessário ressemantizar tais "divergências", por meio do conceito de formas complexas do discurso (BENVENISTE, 1989).

Palavras-chave: Enunciação. Gêneros orais. Ensino.

\section{INTRODUÇÃO}

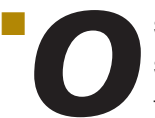

s estudos linguísticos sobre a oralidade e sobre o texto oral têm apresentado desenvolvimento próspero, desde os primeiros estudos do professor Luis Antônio Marcuschi e do grupo de pesquisa da Gramática do Português Falado, do professor Ataliba de Castilho, há mais de 30 anos. Nessa trajetória, o texto falado tem sido descrito e analisado nos diversos níveis de análise linguística (fonológico, morfológico, sintático, semântico, pragmático etc.). Diante da profícua produção intelectual de inúmeros linguistas ${ }^{1}$, a questão que se impõe é: como o professor de língua portuguesa pode estabelecer critérios de avaliação que sejam relevantes e suficientemente adequados às mais diversas situações de ensino? 
Em pesquisa anterior, Silva e Della Méa (2018) categorizaram e analisaram 40 respostas de estudantes de duas universidades federais do Rio Grande do Sul sobre 12 critérios de avaliação de três gêneros orais (seminário com arguição, entrevista e debate regrado). Assim, nosso ponto de partida se deu com a testagem dos seguintes critérios avaliativos, baseados na noção de gênero de Bakhtin (2003):

1. Observância dos papéis sociais dos participantes.

2. Respeito às trocas de turno.

3. Grau de formalidade específico ao gênero.

4. Organização frasal e de tópicos de fala adequados.

5. Seleção léxica adequada e consistente.

6. Manutenção do tema.

7. Capacidade de argumentação em defesa das ideias.

8. Adequação da voz.

9. Adequação da linguagem corporal (olhar, mãos, gestos etc.).

10. Capacidade de exposição e reflexão imediata sobre o tema (cumprimento do objetivo da situação comunicativa).

11. Capacidade de promover/incitar a fala do outro.

12. Planejamento prévio da interação comunicativa.

Aos critérios, os estudantes deveriam atribuir uma das seguintes avaliações: muito relevante, relevante, pouco relevante ou não se aplica. Na análise, as autoras optaram por selecionar os três critérios assinalados como mais relevantes pelos alunos, pois entenderam que eles seriam suficientes para estabelecer parâmetros gerais de avaliação de textos orais. No entanto, ao final da pesquisa, observaram haver empate no "grau de importância" atribuído pelos entrevistados a critérios dos três gêneros orais em estudo. Surpreendeu-nos que, de nove critérios, houve empate em sete deles. Esse resultado nos mostra a necessidade de tomar duas decisões: primeira, conhecer as opiniões de especialistas em língua (professores de lingua portuguesa); segunda, repensar os critérios, reagrupando-os sem categorizá-los em hierarquias diferentes.

Com o recurso à opinião dos especialistas em língua, não pretendemos incorrer no erro da gramática tão apontado pela (própria) linguística: o de se afastar do saber do falante (a esse propósito, ver NORMAND, 2009) e privilegiar um enfoque normativo da língua. Nosso objetivo é trazer as avaliações de professores não como autoridade para a distinção de critérios linguísticos, mas para repensar os próprios critérios previamente estabelecidos, ressemantizando-os e renunciando-os em outros termos, sem que o foco recaia sobre a normatização da língua em sua realização.

Nesse sentido, são considerados, para essa análise, as respostas dos estudantes e os resultados das entrevistas com 22 professores de lingua de instituições de escolas estaduais, escolas particulares, universidades federais e universidades privadas. A fim de estabelecer os termos em que serão ressemantizados os critérios linguísticos, faremos, na seção a seguir, uma retomada de questões 
enunciativas na acepção benvenistiana. Acreditamos que a teoria da Enunciação, proposta por Émile Benveniste, nos ajude a resolver esses dilemas por considerar a língua em sua realização e apresentar um aparelho formalizado para a explicitação dos procedimentos analíticos.

\section{O FUNCIONAMENTO ENUNCIATIVO DA LÍNGUA}

É pertinente historiar sobre o percurso adotado até chegarmos à proposta aqui registrada. Em Silva e Della Méa (2018), registrou-se um caminho pauta$\mathrm{do}^{2}$, inicialmente, pela noção de gênero de Bakhtin e delineou-se 12 critérios generalizantes, supracitados, estabelecidos para dar conta da avaliação de gêneros orais. A essa proposta, agrupou-se o que Schneuwly e Dolz (2004) definiram como "pistas" para avaliação do oral, o que permitiu a formalização inicial de critérios gerais pertinentes ao processo avaliativo de gêneros orais. Buscamos, então, a testagem dos critérios a fim de centrarmos o foco nas "estabilidades" que caracterizam cada gênero estudado.

Cabe lembrar que a acepção teórica aqui adotada tem na Linguística da Enunciação ${ }^{3}$, proposta por Flores e Teixeira (2005), o suporte para o desenvolvimento teórico e metodológico que estabelecemos. Nesta etapa da pesquisa, elegemos, mais especificamente, a Teoria da Enunciação, conforme as considerações sobre o homem na língua propostas por Émile Benveniste (1989), no intuito de ressemantizar os critérios avaliativos eleitos.

Nesse sentido, a fim de delinearmos as reflexões que nos conduzem, selecionamos o capítulo de 1970 "O aparelho formal da enunciação", por meio do qual Benveniste (1989) formaliza a base do horizonte teórico que se configurou nos estudos da enunciação. Para Flores (2013, p. 161), "O aparelho [...] condensa os mais de 60 anos de reflexão linguística sobre a enunciação. Trata-se, portanto, de um momento-sintese da obra enunciativa de Benveniste". Por meio desse artigo, evidencia-se a oposição entre a linguística da língua (emprego das formas) e a de enunciação (emprego da língua), sendo que a enunciação pressupõe a língua, pois é concebida como "este colocar em funcionamento a língua por um ato individual de utilização” (BENVENISTE, 1989, p. 82, grifo nosso).

Ao abordar os fenômenos da língua em uso (no discurso), Benveniste define a enunciação como o próprio ato de produzir o enunciado, sendo o enunciado um produto da enunciação. Essa proposta de 1970 permite ser aplicada a todas as línguas e é capaz de dar conta do sentido no âmbito semântico ${ }^{4}$ da língua, conforme a própria definição de âmbitos de significação do autor. Ainda, esse capítulo sintetiza a proposta benvenistiana de "ultrapassar" a linguística da língua; de ir além do estudo da língua como sistema combinatório para instaurar, na análise do emprego da língua, significações oriundas dessa nova dimensão de significância da língua - trata-se do estabelecimento da enuncia-

2 No artigo "Avaliação de gêneros orais: critérios em debate", Silva e Della Méa (2018) estabelecem uma perspectiva teóricometodológica para avaliação de produções orais pautada na percepção de estudantes universitários.

3 De acordo com Flores e Teixeira (2005), a expressão Linguística da Enunciação abarca uma série de teorias que têm como elemento comum o tratamento da enunciação na linguagem mesmo que por diversos vieses teórico-metodológicos. Nessa perspectiva, os autores falam de "teorias da enunciação (no plural) e em Linguística da Enunciação (no singular)" (FLORES; TEIXEIRA, 2005, p. 8), acepção a qual nos agregamos.

4 Para maior entendimento dos âmbitos de significância da língua, sugere-se a leitura do capítulo "A semiologia da língua", de Émile Benveniste (1989). 
ção como objeto de estudo: fenômeno "tão banal que parece se confundir com a própria língua, tão necessário que nos passa despercebido" (BENVENISTE, 1989, p. 82).

Nessa perspectiva, a enunciação é o próprio ato de produzir um enunciado, que, segundo o autor, pode ser entendido sob três principais aspectos: a realização vocal da língua; o aspecto da semantização; e o quadro formal de realização da enunciação.

Da articulação desses três aspectos da enunciação, Benveniste (1989, p. 83) propõe que se considere, sucessivamente, o ato de enunciação, a situação em que o ato se realiza e os instrumentos de realização da enunciação. Nas palavras de Flores (2013, p. 166), é o "estudo dos caracteres formais da enunciação", sendo registrado que Benveniste propõe "um verdadeiro caminho metodológico" de análise linguística da enunciação.

Assim, promover o ato de enunciar, um locutor apropria-se da língua e a converte em discurso. É pela enunciação, então, que a língua é convertida em discurso, sendo o locutor condição necessária para a realização do ato, pois, sem ele, a língua continua sendo apenas mera possibilidade. Com o ato de enunciar, o locutor converte a língua em discurso e postula um alocutário, criando, assim, uma rede de relações na qual uma enunciação suscita outra de retorno. Sendo um processo de apropriação da língua, via ato individual de um locutor, a enunciação, explícita ou implicitamente, é uma alocução, na medida em que implanta, sempre, um alocutário no ato de sua realização. É nesse sentido que Benveniste (1989, p. 87) caracteriza a enunciação como "a acentuação da relação discursiva com o parceiro, seja este real ou imaginado, individual ou coletivo". Esse é o quadro figurativo da enunciação, o da estrutura do diálogo.

Na enunciação, informa Benveniste (1989, p. 84), a "língua se acha empregada para a expressão de uma certa relação com o mundo", referência essa que passa a ser entendida como uma forma de o locutor referir e de o alocutário correferir pelo discurso. A referência, para o autor, integra a enunciação, o que permite entender que ela se cria e se estabelece pela enunciação, portanto, não há referência ao mundo na teoria benvenistiana - a referência é à enunciação que inclui as categorias de pessoa (eu/tu), tempo (agora) e espaço (aqui).

A enunciação comporta, portanto, no próprio ato de enunciar, locutor e alocutário (figuras igualmente necessárias); somadas à categoria de pessoa (eu/tu), encontram-se, sempre, as categorias de tempo e espaço, pois a situação em que o ato se realiza e o tempo de sua realização refletem sentidos promovidos pelo locutor que, ao se apropriar da língua, produz sempre um uso novo e irrepetível.

Diante desses aspectos gerais da enunciação, Benveniste (1989) propõe uma discussão sobre o diálogo. Sendo esse considerado o quadro figurativo da enunciação, o autor questiona se há diálogo fora da enunciação ou ainda se há enunciação sem diálogo. Encaminha-se, então, a abertura para análise das formas complexas do discurso por desdobramentos a serem considerados a partir da descrição da forma linguística e do quadro figurativo das enunciações.

Dessa forma, Benveniste esboçou um quadro formal para análise do emprego da língua, estabelecendo como centro da enunciação o "eu (tu)" - sujeito que mobiliza o sistema e o converte em discurso. 


\section{Caminho metodológico}

Como procedimentos de análise dos dados, os estudantes universitários (40 estudantes, sendo 20 da UFSM e 20 da UFRGS) e os professores de língua (22 professores com titulação mínima de mestre e que atuam em instituições diversas, como universidade pública, universidade privada, escola pública e escola privada), responderam ao mesmo questionário, elaborado com o recurso do Google Forms e encaminhado por e-mail, durante o primeiro semestre de 2017. Os 12 critérios mencionados foram apreciados por todos os participantes. Com os resultados compilados, elaboramos procedimentos metodológicos no intuito de ressemantizar os critérios. Seguem as etapas adotadas:

1. Retomada dos dados dos alunos (resultado de SILVA; DELLA MÉA, 2018).

2. Exposição dos resultados dos professores para os três gêneros.

3. Explicitação e comentários sobre os critérios de avaliação de gêneros que obtiveram empate no estabelecimento da relevância para os três gêneros (seminário com arguição, entrevista e debate regrado).

4. Explicitação e comentários sobre os dados que tiveram o mesmo resultado para alunos e professores.

5. Explicitação e comentários sobre os dados que tiveram resultado diferente para alunos e professores.

6. Ressemantização, por meio da análise enunciativa, dos critérios apontados como muito relevantes e que foram divergentes entre os grupos de respondentes.

\section{Resultados}

Para promover a organização estrutural dos resultados desta pesquisa, iniciamos com a retomada dos dados considerados "muito relevantes" pelos 40 alunos respondentes (SILVA; DELLA MÉA, 2018) e colocamos esses dados lado a lado às respostas elencadas como "muito relevantes" pelos 22 professores, para a observância sobre quais critérios eram recorrentes em ambos os grupos de respondentes. Observamos e elencamos, ainda, os critérios que pertenciam a apenas um ou outro grupo e, da intersecção desses critérios, chegamos a critérios que consideramos orientadores para a análise enunciativa dos gêneros em questão.

Para os três gêneros, os passos adotados foram os mesmos; entretanto, cada gênero apresenta particularidades surgidas das próprias respostas dos participantes. Diante disso, cabe realizar a explicitação das respostas e os comentários cabiveis de acordo com as especificidades de cada gênero. Portanto, para fins analiticos, trabalhamos com os três gêneros separadamente e na seguinte ordem: seminário com arguição, entrevista e debate regrado.

\section{Seminário com arguição}

Iniciamos nossa proposta de análise para ressemantização de critérios avaliativos apresentando, no Quadro $1^{5}$, os resultados da seleção dos critérios (por

\footnotetext{
5 Todos os quadros apresentados neste artigo foram elaborados pelas autoras
} 
alunos/professores) e após discutimos questões relativas aos resultados encontrados.

Quadro 1 - Critérios considerados essenciais ao gênero "seminário com arguição"

\begin{tabular}{|c|c|c|}
\hline $\begin{array}{c}\text { Critérios muito } \\
\text { relevantes elencados } \\
\text { pelos alunos }\end{array}$ & $\begin{array}{l}\text { Critérios muito } \\
\text { relevantes elencados } \\
\text { pelos professores }\end{array}$ & $\begin{array}{c}\text { Intersecção dos } \\
\text { resultados (critérios } \\
\text { comuns para professores } \\
\text { e alunos) }\end{array}$ \\
\hline $\begin{array}{l}\text { Capacidade de } \\
\text { argumentação em defesa } \\
\text { das ideias. }\end{array}$ & $\begin{array}{l}\text { Capacidade de exposição e } \\
\text { de reflexão imediata sobre } \\
\text { o tema. }\end{array}$ & $\begin{array}{l}\text { Capacidade de } \\
\text { argumentação em defesa } \\
\text { das ideias. }\end{array}$ \\
\hline $\begin{array}{l}\text { Planejamento prévio da } \\
\text { interação comunicativa. }\end{array}$ & $\begin{array}{l}\text { Seleção léxica adequada } \\
\text { e consistente. }\end{array}$ & $\begin{array}{l}\text { Seleção léxica adequada } \\
\text { e consistente. }\end{array}$ \\
\hline $\begin{array}{l}\text { Seleção léxica adequada } \\
\text { e consistente. }\end{array}$ & $\begin{array}{l}\text { Planejamento prévio da } \\
\text { interação comunicativa. }\end{array}$ & $\begin{array}{l}\text { Planejamento prévio da } \\
\text { interação comunicativa. }\end{array}$ \\
\hline $\begin{array}{l}\text { Observância dos papéis } \\
\text { sociais dos participantes. }\end{array}$ & $\begin{array}{l}\text { Capacidade de } \\
\text { argumentação em defesa } \\
\text { das ideias. }\end{array}$ & $\begin{array}{l}\text { Capacidade de exposição } \\
\text { e de reflexão imediata } \\
\text { sobre o tema. }\end{array}$ \\
\hline $\begin{array}{l}\text { Capacidade de exposição } \\
\text { e de reflexão imediata } \\
\text { sobre o tema. }\end{array}$ & $\begin{array}{l}\text { Adequação da linguagem } \\
\text { corporal. } \\
\text { Adequação da voz. }\end{array}$ & \\
\hline
\end{tabular}

É preciso registrar que os três critérios apontados, inicialmente, como "muito relevantes" pelos alunos apresentaram empates numéricos (número de votantes) nos segundo e terceiro lugares, ou seja, tivemos dois critérios em segundo e dois em terceiro lugar com número de votação idêntica (SILVA; DELLA MÉA, 2018). Diante disso, nossa opção metodológica foi adotar os itens empatados como critérios igualmente válidos e muito relevantes para o gênero. Constituímos, então, um elenco de cinco critérios avaliados como "muito relevantes" apontados pelos alunos.

Quanto à observação dos resultados dos especialistas em linguagem, os chamados "conhecedores", conforme Normand (2009), a proposta era complementar a reflexão dos alunos e, quem sabe, promover desempate em casos apontados com igual número de respostas pelos alunos. Entretanto, observamos que também entre os professores houve empate no número de votantes, só que foi somente no terceiro lugar e com quatro critérios distintos com igual votação. Nossa opção foi a mesma adotada com relação aos critérios em empate apontados pelos alunos: adotamos os itens empatados como válidos e obtivemos, então, seis critérios válidos e considerados "muito relevantes" pelos professores para o ato de avaliar o gênero em questão. Cabe observar que os seis critérios elencados pelos professores foram apontados como "muito relevantes" por mais de $50 \%$ dos docentes que responderam ao formulário, de forma que, se dos 22 
professores, sempre mais de 11 apontaram esses critérios como "muito relevantes", tal porcentagem confere certa legitimidade na adoção desses critérios como válidos para a avaliação desse gênero.

Quanto aos critérios elencados, quatro são comuns aos professores e alunos ("capacidade de argumentação em defesa das ideias"; "seleção léxica adequada e consistente"; "planejamento prévio da interação comunicativa"; "capacidade de exposição e de reflexão imediata sobre o tema") e, na opinião dos respondentes, três não convergem:

Guadro 2 - Critérios que divergem conforme o grupo de respondentes

\begin{tabular}{|l|l|}
\hline \multicolumn{1}{|c|}{$\begin{array}{c}\text { Critério muito relevante } \\
\text { elencado somente pelos alunos }\end{array}$} & $\begin{array}{c}\text { Critérios "muito relevantes" } \\
\text { elencados somente pelos professores }\end{array}$ \\
\hline $\begin{array}{l}\text { Observância dos papéis sociais dos } \\
\text { participantes. }\end{array}$ & Adequação da linguagem corporal. \\
\cline { 2 - 2 } & Adequação da voz. \\
\hline
\end{tabular}

Entendemos que a divergência relativa à questão corporal revela um dos distanciamentos entre o que os professores propõem e o que os alunos creem sobre o processo avaliativo do oral. Acreditamos que essa diferença se dá pelo fato de os aspectos corporais não serem, normalmente, trabalhados nas disciplinas de lingua (portuguesa e/ou adicional) na escola, portanto, os alunos não o concebem como um elemento a ser observado no emprego da língua. Entretanto, os professores o percebem como muito relevante, por entenderem que tudo o que acompanha a enunciação significa e é agregado ao exercício oral. Essa divergência indica a necessidade de novos estudos na área, no Brasil, em especial aqueles que tragam uma abordagem descritiva e aplicada a esse aspecto.

Quanto à questão da adequação da voz (altura, intensidade, articulação etc.), é possivel entender que o trabalho com leitura em voz alta e/ou com outras atividades orais não atribui espaço suficiente para o desenvolvimento de aspectos prosódicos: por isso, os alunos não o selecionaram, por não perceberem ênfase no quesito da voz, do gesto, da mímica nas práticas com a linguagem em sala de aula. Já a relevância dos papéis sociais dos participantes, observada somente pelos alunos, parece indicar certo comportamento pragmático dos alunos diante da atividade proposta, pois, em sala de aula, mesmo em momentos de interação verbal, mantém-se a noção hierárquica do papel docente. Tal critério não é referido como muito relevante pela maioria dos docentes; somente oito sinalizaram-no dessa forma.

\section{Entrevista}

Com relação ao gênero oral "entrevista", o Quadro 3 apresenta os resultados relativos à relevância de critérios apontados pelo grupo de alunos e pelos professores de línguas, com o resultado da intersecção entre os grupos respondentes. A discussão desses resultados é registrada na sequência. 
Quadro 3 - Critério considerados essenciais ao gênero "entrevista”

\begin{tabular}{|c|c|c|}
\hline $\begin{array}{l}\text { Critérios muito relevantes } \\
\text { elencados pelos alunos }\end{array}$ & $\begin{array}{l}\text { Critérios muito } \\
\text { relevantes elencados } \\
\text { pelos professores }\end{array}$ & $\begin{array}{c}\text { Intersecção dos } \\
\text { resultados } \\
\text { (critérios comuns para } \\
\text { professores e alunos) }\end{array}$ \\
\hline $\begin{array}{l}\text { Planejamento prévio da } \\
\text { interação comunicativa. }\end{array}$ & $\begin{array}{l}\text { Planejamento prévio da } \\
\text { interação comunicativa. }\end{array}$ & $\begin{array}{l}\text { Planejamento prévio da } \\
\text { interação comunicativa. }\end{array}$ \\
\hline $\begin{array}{l}\text { Capacidade de exposição e } \\
\text { reflexão imediata sobre o tema. }\end{array}$ & $\begin{array}{l}\text { Capacidade de incitar a } \\
\text { fala do outro. }\end{array}$ & $\begin{array}{l}\text { Capacidade de incitar } \\
\text { a fala do outro. }\end{array}$ \\
\hline $\begin{array}{l}\text { Capacidade de incitar a fala } \\
\text { do outro. }\end{array}$ & $\begin{array}{l}\text { Respeito às trocas de } \\
\text { turno. }\end{array}$ & $\begin{array}{l}\text { Respeito às trocas de } \\
\text { turno. }\end{array}$ \\
\hline Respeito às trocas de turno. & & \\
\hline $\begin{array}{l}\text { Seleção léxica adequada } \\
\text { e consistente. }\end{array}$ & & \\
\hline
\end{tabular}

Os três critérios apontados como "muito relevantes" pelos "conhecedores da língua" (professores) não passaram por empates entre eles ou com outros critérios em nenhum momento. Houve quase unanimidade nas respostas dos docentes: "planejamento prévio da interação comunicativa" (19); "capacidade de incitar a fala do outro" (18); e "respeito às trocas de turno" (17 dos 22 respondentes). Entretanto, houve discordância nos registros dos alunos, o que resultou em cinco critérios adotados em consequência do empate no número de votantes. Os critérios "capacidade de exposição e reflexão imediata sobre o tema", "capacidade de incitar a fala do outro", "respeito às trocas de turno" e "seleção léxica adequada e consistente" são, respectivamente, os segundos e terceiros critérios empatados e mais votados pelos alunos. Adotamos, então, esses quatro critérios como válidos para nossa análise, assim como o fizemos com os outros gêneros que apresentavam empates em número de votantes dos critérios.

Com relação ao critério "planejamento prévio da interação comunicativa", os alunos concordaram sobre ele ser muito relevante para definição de características a serem observadas por ocasião de avaliação do gênero. Esse critério foi apontado, portanto, por alunos e também por professores como o mais relevante do processo. A "capacidade de incitar a fala do outro" e o "respeito às trocas de turno" foram os dois critérios eleitos pelos professores e que permitiram o desempate nas respostas dos alunos. Assim, obtivemos três critérios comuns aos respondentes e apontados como essenciais para a análise do gênero entrevista e dois que mostram a opinião divergente dos alunos em relação aos docentes.

Guadro 4 - Critérios que divergem conforme o grupo de respondentes

\section{Critérios muito relevantes elencados somente pelos alunos}

Capacidade de exposição e reflexão Seleção léxica adequada e consistente.

imediata sobre o tema. 
Por nossa perspectiva analítica, selecionamos somente os critérios que foram sinalizados como "muito relevantes" pelos grupos de respondentes. Entretanto, é preciso refletir sobre os critérios "seleção léxica adequada e consistente" e "capacidade de exposição e de reflexão imediata sobre o tema", que foram enquadrados entre as categorias de "muito relevantes" e "relevantes" por 21 dos docentes. Ou seja, há certa concordância sobre o valor desses critérios para constituição do gênero, o que diverge é o grau valorativo atribuído pelos respondentes. Nesse sentido, a fim de nos mantermos no caminho metodológico traçado, que adota somente os critérios "muito relevantes" apontados, não os incluiremos em nossa análise inicial; entretanto, salientamos que a divergência na valoração constatada não os coloca em lugar de distanciamento entre o que os alunos propõem e o que os docentes sinalizam.

\section{Debate regrado}

Com relação ao gênero oral "debate regrado", o quadro a seguir apresenta os resultados relativos à relevância de critérios apontados pelo grupo de alunos e pelos professores de línguas, com o resultado da intersecção entre os grupos respondentes. A discussão desses resultados é registrada na sequência.

Quadro 5 - Critérios considerados essenciais ao gênero "debate regrado"

\begin{tabular}{|l|l|l|}
\hline \multicolumn{1}{|c|}{$\begin{array}{c}\text { Critérios muito } \\
\text { relevantes elencados } \\
\text { pelos alunos }\end{array}$} & \multicolumn{1}{|c|}{$\begin{array}{c}\text { Critérios muito } \\
\text { relevantes elencados } \\
\text { pelos professores }\end{array}$} & $\begin{array}{c}\text { Interseç̧ão dos } \\
\text { resultados } \\
\text { (critérios comuns para } \\
\text { professores e alunos) }\end{array}$ \\
\hline $\begin{array}{l}\text { Capacidade de } \\
\text { argumentação em defesa } \\
\text { das ideias. }\end{array}$ & $\begin{array}{l}\text { Capacidade de } \\
\text { argumentação em defesa } \\
\text { das ideias. }\end{array}$ & $\begin{array}{l}\text { Capacidade de } \\
\text { argumentação em defesa } \\
\text { das ideias. }\end{array}$ \\
$\begin{array}{l}\text { Respeito às trocas de } \\
\text { turno. }\end{array}$ & $\begin{array}{l}\text { Capacidade de incitar a } \\
\text { fala do outro. }\end{array}$ & Manutenção do tema. \\
$\begin{array}{l}\text { Capacidade de exposição } \\
\text { e reflexão imediata sobre } \\
\text { o tema. }\end{array}$ & $\begin{array}{l}\text { Observância dos papéis } \\
\text { sociais dos participantes. }\end{array}$ & $\begin{array}{l}\text { Planejamento prévio da } \\
\text { interação comunicativa. }\end{array}$ \\
$\begin{array}{l}\text { Planejamento prévio da } \\
\text { interação comunicativa. }\end{array}$ & $\begin{array}{l}\text { Observância dos papéis } \\
\text { interação comunicativa. }\end{array}$ \\
$\begin{array}{l}\text { Observância dos papéis } \\
\text { sociais dos participantes. }\end{array}$ & $\begin{array}{l}\text { Capacidade de exposição } \\
\text { e reflexão imediata sobre } \\
\text { o tema. }\end{array}$ & $\begin{array}{l}\text { Capacidade de exposição } \\
\text { e reflexão imediata sobre } \\
\text { o tema. }\end{array}$ \\
$\begin{array}{l}\text { Seleção léxica adequada } \\
\text { e consistente. }\end{array}$ & Manutenção do tema. \\
Manutenção do tema. & $\begin{array}{l}\text { Organização frasal e de } \\
\text { tópicos de fala adequados. }\end{array}$ & \\
\hline
\end{tabular}


Em relação ao gênero "debate regrado", seguimos os mesmos procedimentos relativos aos empates encontrados nos resultados dos outros gêneros estudados - adotamos os critérios em empate como elementos "muito relevantes" apontados pelos respondentes. Com isso, obtivemos sete critérios "muito relevantes", tanto de alunos, quanto de docentes, mas com apenas cinco em comum. Os professores foram quase unânimes (19 das 22 respostas) em apontar "capacidade de argumentação em defesa das ideias" como o critério mais relevante a ser considerado, fato observado também nos resultados concernentes aos alunos (34 das 40 respostas), ou seja, não há dúvidas sobre a valoração desse critério. Porém, o empate nos demais critérios revela um pouco a dificuldade em estabelecer prioridades (não excludentes, mas valorativas) com relação a esse gênero.

Ressaltamos que dos 12 critérios iniciais que propusemos para essa pesquisa, um total de nove foram avaliados nesse gênero como "muito relevantes" pelos participantes. Dos sete critérios apontados por cada grupo de respondentes, cinco são comuns aos grupos (conforme Quadro 5), e quatro deles, dois de cada grupo, manifestam, mais uma vez, a divergência na análise de gêneros orais.

Quadro 6 - Critérios que divergem conforme o grupo de respondentes

\begin{tabular}{|l|l|}
\hline \multicolumn{1}{|c|}{$\begin{array}{c}\text { Critérios muito relevantes } \\
\text { elencados somente pelos alunos }\end{array}$} & \multicolumn{1}{|c|}{$\begin{array}{c}\text { Critérios muito relevantes } \\
\text { elencados somente pelos professores }\end{array}$} \\
\hline Respeito às trocas de turno. & Capacidade de incitar a fala do outro. \\
\hline Seleção léxica adequada e consistente. & $\begin{array}{l}\text { Organização frasal e de tópicos de fala } \\
\text { adequados. }\end{array}$ \\
\hline
\end{tabular}

Cabe retomar aqui a ideia de que o debate regrado é um gênero oral público, mas que está, em situação de ensino e aprendizagem, ocupando um espaço público, mas imaginário, já que a atividade parece ser mais uma encenação do real, pois, embora seja uma enunciação, é uma enunciação representada. Diante deste quadro de "encenação teatral", a abundância dos critérios divergentes sugere haver certa idealização do "lugar" público a ser ocupado, de maneira que esses critérios divergentes apontam para determinadas práticas nada unívocas e marcadas na realização da língua.

A particularidade da situação comunicativa comporta como critérios "muito relevantes", segundo os respondentes, diferentes atos ligados à pragmática da língua (respeitar os turnos conversacionais e incitar o "alocutário" a falar) e recursos linguísticos (léxico e organização frasal). Manteremos nossa perspectiva metodológica que adota somente os critérios "muito relevantes" em concordância entre os dois grupos de respondentes. Entretanto, registramos que há certa convergência entre os grupos no sentido de apontarem para as mesmas duas grandes categorias da lingua. Na gramatical, assinalamos o léxico (proposto pelos alunos) e a organização frasal (indicada pelos docentes) e, na pragmática, apontamos o respeito aos turnos conversacionais (proposto pelos alunos) e o incitar a fala do outro (indicado pelos docentes). Dessa forma, embora tenhamos quatro critérios diferentes propostos pelos dois grupos, temos as mesmas categorias da lingua indicadas. 


\section{RESSEMANTIZANDO OS CRITÉRIOS AVALIATIVOS DIVERGENTES DOS GÊNEROS ESTUDADOS}

Faremos agora uma releitura dos critérios que tiveram divergências entre professores e alunos. Para isso, utilizaremos a obra $O$ aparelho formal da enunciação, de Benveniste (1989), em especial o conceito de formas complexas do discurso. Nesse sentido, buscamos entender e atender as complexidades das demandas enunciativas de professores e alunos, sem excluir nenhuma delas.

Vejamos a caracterização que Benveniste nos oferece do conceito de formas complexas do discurso, conceito que aplica a situações de discurso em que não há uma relação clara entre diálogo eu/tu e enunciação eu/tu, ou seja, há uma diferença entre o "parceiro, o tu", como "real ou imaginado, individual ou coletivo" (BENVENISTE, 1989, p. 87). Complementa a definição com o seguinte: "Essas situações exigiriam uma dupla descrição, da forma linguística e da condição figurativa" (BENVENISTE, 1989, p. 88).

Dessa forma, entendemos que, por exemplo, é possivel ver que a importância dada pelos alunos à "observação dos papéis sociais dos parceiros" e da "linguagem corporal" e "adequação da voz" dada por professores em relação ao gênero seminário oral (Quadro 2), pode ser ressementizada da seguinte forma, constituindo um "novo" critério: a observação dos papéis sociais, além de ser marcada em atitudes linguísticas, também pode ser percebida em atitudes corporais (gestos, voz etc.). Em sintese: "observância dos papéis sociais em seus aspectos linguístico e corporal".

Relativos ao gênero entrevista, os critérios "seleção léxica adequada e consistente" e "capacidade de exposição e reflexão imediata sobre o tema" marcam um descompasso em relação ao quadro figurativo na percepção dos alunos. A relevância apontada pelos alunos não é negada pelos docentes, apenas é atenuada. Com o intuito de ressemantizar e com isso redesenhar a relação dos parceiros envolvidos no quadro em que se configuram os critérios avaliativos, elaboramos um novo critério para avaliação desse gênero, sintetizado como: "capacidade de exposição do tema, com seleção léxica consistente".

As "trocas de turno", o "incitar o outro", o "léxico" e a "organização frasal" são critérios relativos ao gênero debate regrado que requerem observações: é preciso lembrar que os critérios elencados ora por alunos ora por docentes não são excludentes, ou seja, é possivel promover ressignificações sem que sejam feitas seleções e/ou exclusões; também, cabe buscar o conceito de procedimentos acessórios e considerar esses critérios como singularidades na análise de cada grupo e, por fim, construir um novo critério para esse gênero, com base no conceito de formas complexas do discurso que impelem à ressemantização "da forma linguística e da condição figurativa”. Nesse sentido, a capacidade de fazer o outro falar implica em organização linguística formal e pragmática, de maneira que o novo critério para esse gênero ficou estabelecido como: "capacidade de incitar a fala do outro, com seleção léxica consistente, organização frasal e respeitando os turnos conversacionais".

\section{CONSIDERAÇÕES FINAIS}

Apresentamos, a seguir, um quadro com os critérios considerados muito relevantes para os gêneros orais em análise. Acreditamos que este quadro pode 
auxiliar professores a estabelecer tanto critérios de avaliação quanto o próprio planejamento da aula. Observa-se que o maior número de critérios para o gênero debate regrado deve-se ao fato de esse gênero ser pouco explorado tanto na literatura especializada, quanto na própria experiência discente e docente nas salas de aula.

Quadro 7 - Critérios de avaliação de gêneros orais

\begin{tabular}{|c|c|c|}
\hline $\begin{array}{l}\text { Gênero "seminário com } \\
\text { arguição" (critérios para } \\
\text { avaliação) }\end{array}$ & $\begin{array}{l}\text { Gênero "entrevista" } \\
\text { (critérios para } \\
\text { avaliação) }\end{array}$ & $\begin{array}{l}\text { Gênero "debate regrado" } \\
\text { (critérios para avaliação) }\end{array}$ \\
\hline $\begin{array}{l}\text { Capacidade de } \\
\text { argumentação em defesa } \\
\text { das ideias. }\end{array}$ & $\begin{array}{l}\text { Planejamento prévio à } \\
\text { interação comunicativa. } \\
\text { Capacidade de incitar }\end{array}$ & $\begin{array}{l}\text { Capacidade de } \\
\text { argumentação em defesa } \\
\text { das ideias. }\end{array}$ \\
\hline $\begin{array}{l}\text { Seleção léxica adequada } \\
\text { e consistente. }\end{array}$ & a fala do outro. & Manutenção do tema. \\
\hline $\begin{array}{l}\text { Planejamento prévio da } \\
\text { interação comunicativa. }\end{array}$ & $\begin{array}{l}\text { Respeito às trocas de } \\
\text { turno. }\end{array}$ & $\begin{array}{l}\text { Planejamento prévio à } \\
\text { interação comunicativa. }\end{array}$ \\
\hline $\begin{array}{l}\text { Capacidade de exposição } \\
\text { e de reflexão imediata }\end{array}$ & $\begin{array}{l}\text { Capacidade de exposição } \\
\text { do tema, com seleção } \\
\text { léxica consistente. }\end{array}$ & $\begin{array}{l}\text { Observância dos papéis } \\
\text { sociais dos participantes. }\end{array}$ \\
\hline $\begin{array}{l}\text { sobre o tema. } \\
\text { Observância dos papéis } \\
\text { sociais em seus aspectos }\end{array}$ & & $\begin{array}{l}\text { Capacidade de exposição } \\
\text { e reflexão imediata sobre } \\
\text { o tema. }\end{array}$ \\
\hline linguístico e corporal. & & $\begin{array}{l}\text { Capacidade de incitar a fala } \\
\text { do outro, com seleção léxica } \\
\text { consistente, organização } \\
\text { frasal e respeitando os } \\
\text { turnos conversacionais. }\end{array}$ \\
\hline
\end{tabular}

Um possivel desdobramento de pesquisa poderia ser compreender como a utilização desse gênero amplia a capacidade dos alunos em atividades de outros gêneros orais. Se, como diz Bakhtin (2003), um gênero é um elo em uma cadeia de gêneros, entendemos que o gênero debate regrado é um dos mais complexos gêneros orais, apresentando características interacionais fundamentais na entrevista e características de conteúdo linguístico fundamentais ao seminário. Dessa forma, a complexidade do gênero debate regrado consiste no fato de que ele reúne as características relevantes dos dois outros gêneros orais, sendo um gênero "híbrido". Considerando os conceitos de gêneros primários e secundários de Bakhtin, essa observação indica-nos uma possibilidade de sequência do ensino dos gêneros orais ao longo do ensino fundamental e médio: entrevista; seminário; e debate regrado.

Uma palavra final sobre a ressemantização como recurso para resolução de divergências: sempre que se pesquisa sobre um fato linguístico que envolve mais de um ponto de vista, é necessário "resolvê-lo" pelo recurso de uma ressemanti- 
zação. Como nos ensina Benveniste (1988, p. 286), a relação eu/tu, professor/ aluno, é sempre inversível porém não simétrica, recíproca porém não polarizável, logo, há que se pensar em uma dialética própria da língua. Foi com o conceito de formas complexas do discurso que acessamos e interpretamos essa dialética.

\section{Criteria For the eVAlUATION OF ORAL GENRES: LANGUAGE'S ENUNCIATIVE PERSPeCtive}

Abstract: Considering the Enunciation Linguistics proposed by Flores and Teixeira (2005) and Flores (2013), we seek to promote some criteria for the evaluation of oral genres produced in teaching and learning environments. Based on the oral genres: 1 . seminar with argument; 2 . interview; and 3. regulated debate, twenty-two teachers answered an online form about the evaluation these oral genres. Divergences in the evaluation were observed, fact that made a ressemantization of those "divergences" necessary, by means of the use of the concept of complex speech forms (BENVENISTE, 1989).

Keywords: Enunciation. Spoken production. Teaching.

\section{REFERÊNCIAS}

BAKHTIN, M. Estética da criação verbal. São Paulo: Martins Fontes, 2003. BENVENISTE, É. Da subjetividade na linguagem. In: BENVENISTE, É. Problemas de linguistica geral I. Campinas: Pontes, 1988.

BENVENISTE, É. O aparelho formal da enunciação. In: BENVENISTE, É. Problemas de linguística geral II. Campinas: Pontes, 1989.

FLORES, V. N. Introdução à teoria enunciativa de Benveniste. São Paulo: Parábola, 2013.

FLORES, V.; TEIXEIRA, M. Introdução à linguística da enunciação. São Paulo: Contexto, 2005.

JUBRAN, C. S. (org.). A construção do texto falado. São Paulo: Contexto, 2015.

MARCUSCHI, L. A. Da fala para a escrita: atividades de retextualização. São Paulo: Cortez, 2001.

MARCUSCHI, L. A. Produção textual, análise de gêneros e compreensão. São Paulo: Parábola Editorial, 2008.

NORMAND, C. Saussure. São Paulo: Editora Liberdade, 2009.

SCHNEUWLY, B.; DOLZ, J. Gêneros orais e escritos na escola. São Paulo: Mercado de Letras, 2004.

SILVA, S.; DELLA MÉA, C. H. P. Avaliação de gêneros orais: critérios em debate. Diálogo das Letras, Pau dos Ferros, v. 7, n. 2, p. 44-60, maio/ago. 2018. Disponivel em: http://periodicos.uern.br/index.php/dialogodasletras/article/view/ 3205/1738. Acesso em: 16 maio 2019. 